\title{
Role of video-assisted thoracic surgery in T4 NSCLC
}

\author{
Debora Brascia $^{1}$, Giulia De Iaco ${ }^{1}$, Marcella Schiavone ${ }^{1}$, Samuele Nicotra ${ }^{2}$, Francesca Signore ${ }^{1}$, \\ Teodora Panza ${ }^{1}$, Alessandro Geronimo ${ }^{1}$, Doroty Sampietro ${ }^{1}$, Giuseppe Marulli ${ }^{1}$
}

${ }^{1}$ Thoracic Surgery Unit, Department of Organ Transplantation and Emergency, University Hospital of Bari, Bari, Italy; ${ }^{2}$ Thoracic Surgery Unit, Department of Cardiologic, Thoracic and Vascular Sciences, University of Padova, Padova, Italy

Contributions: (I) Conception and design: G Marulli, D Brascia; (II) Administrative support: All authors; (III) Provision of study materials or patients: All authors; (IV) Collection and assembly of data: All authors; (V) Data analysis and interpretation: All authors; (VI) Manuscript writing: All authors; (VII) Final approval of manuscript: All authors.

Correspondence to: Prof. Giuseppe Marulli. Thoracic Surgery Unit, Department of Organ Transplantation and Emergency University Hospital of Bari, Italy. Email: giuseppe.marulli@uniba.it; beppemarulli@libero.it.

\begin{abstract}
For many years, T4 lung tumors have been considered less suitable for surgery, because of their local extension invading central structures or vertebral bodies. To date, many studies have confirmed the advantages in terms of survival of a multimodality approach made up of surgical resection associated with neoadjuvant and/or adjuvant therapy for selected patients with advanced lung cancer. In those patients, in fact, minimally invasive surgery could improve overall survival rates while promoting faster recovery, faster access to adjuvant therapies and preserving a better functionality of the immune system. Because of the difficulty in collecting data on patients with T4 lung tumors amenable to minimally invasive surgery, published evidences only come from case reports which prove the feasibility and the possible advantages of video-assisted thoracic surgery (VATS) procedures. The aim of this literature review is to collect the published experiences of skilled surgeons dealing with T4 tumors invading central structures or chest wall, to analyze concerns and new opportunities of treatment and proving the feasibility and advantages of the VATS approach.
\end{abstract}

Keywords: T4 lung tumors; advanced lung cancer; video-assisted thoracic surgery (VATS); minimally invasive

Received: 02 April 2020; Accepted: 03 June 2020; Published: 20 July 2021.

doi: 10.21037/jovs-20-93

View this article at: http://dx.doi.org/10.21037/jovs-20-93

\section{Introduction}

The eighth edition of tumor, node and metastasis (TNM) classification for lung cancer has defined T4 tumors those $>7 \mathrm{~cm}$ or invading the mediastinum, heart, diaphragm, great vessels, trachea, esophagus, spine, recurrent nerve, carina or separate tumor nodule(s) in a different ipsilateral lobe (1).

Because of the local extension of these tumors invading central structures or vertebral bodies, for many years they have been considered less suitable for surgery. To date, many studies confirm the advantage in terms of survival of a multimodality approach made up of surgical resection associated with neoadjuvant and/or adjuvant therapy for selected patients with locally advanced lung tumors (2-4).

In NSCLC, the $\mathrm{p} T$ factor does not significantly affect survival rate as the $\mathrm{pN}$ factor does, except in the case of the $\mathrm{T} 4$ disease, in which survival rates do not statistically differ in the setting of N1 or N2 node involvement (5). In this stage of the disease, 5 -years survival rates range from 22 to $47 \%$ in patients without lymph node involvement and after complete surgical resection (6-13).

Advantages of the thoracoscopic approach have been widely discussed and proved and include decreased postoperative pain, shorter hospitalization and faster recovery (14-19). Along with technical and surgeons' skills acquirements, video-assisted thoracic surgery (VATS) has become a challenging opportunity to treat T4 lung tumors even if published evidence is still sparse. The availability of high definition cameras with wide-angle lens, new devices, more angulated staplers and topical hemostatic tools, 
in fact, has made affordable the thoracoscopic approach even for locally advanced tumors $(20,21)$. Under the assumption that complex procedures as sleeve lobectomies, vessel reconstructions, pneumonectomies, and chest wall resections should be done only by skillful surgeons (21), Nakanishi et al. (22) have suggested a learning curve of 25 cases for minimally-invasive $\mathrm{T} 4$ tumors resections for those expert surgeons who had already performed more than 100 VATS lobectomies in their career.

\section{VATS for T4 lung tumors: still few evidences}

No randomized controlled trials have been published yet about perioperative and long-term outcomes of VATS resections for T4 lung tumors. Because of the difficulty in collecting data on patients with T4 lung tumors amenable to minimally invasive surgery, published evidences only come from case reports which prove the feasibility and the possible advantages of VATS procedures. Moreover, the few existing evidences refer to advanced lung tumors as defined by the 7th American Joint Committee on Cancer TNM staging system: tumors greater than $4 \mathrm{~cm}$, T3 and T4 tumors or tumors requiring neoadjuvant therapy $(20,21)$. Hennon et al. (21) have published results about outcomes after thoracoscopic $v s$. open thoracotomy resection for advanced lung cancer. They proved no statistical differences in median blood loss, operative time, frequency of major complications, in-hospital stay and overall survival between the two approaches. The two groups only differ in the percentage of patients who could undergo adjuvant therapy postoperatively, which was significantly higher in the VATS group $(37.2 \%$ vs. $5.3 \%$ ); conversion rate was $23 \%$. Similar findings have been reported by Chen et al. (23) when comparing thoracoscopic $v s$. open thoracotomy resection for advanced lung cancer. Interestingly, they also found a significant difference between the median blood loss and length of hospital stay, in favor of the thoracoscopic approach. It also seemed that more patients in the VATS group could tolerate all chemotherapy cycles at the fully planned dose than those in the open group $(51.7 \% v s$. $42.5 \%$ ). Gonfiotti et al. (24) published their results on 3,266 vs. 454 patients undergoing VATS resections for early and locally advanced lung tumors, respectively. The hospital stay, mortality and complication rates were not statistically different between the two groups, while VATS resections for advanced-stage NSCLC were associated with a longer procedure time, higher blood loss and an increased incidence of conversion.
Conversion rates vary from $0 \%$ to $23 \%$ for advanced lung tumors, depending on case selection and surgeon expertise (25). Conversion to thoracotomy could be necessary during VATS procedures for advanced stages; the infiltration itself, in fact, can produce massive bleeding or difficulty in achieving a wide oncological resection forcing the surgeon to convert to thoracotomy. Gonfiotti et al. (24) proved that patients requiring conversion had a significantly higher operative time, blood loss, hospital stay and positive surgical margins, but not a higher overall morbidity rate.

Uniportal VATS (u-VATS) has also been proved to be a feasible approach for advanced lung tumors in skillful hands. Fan et al. (26) compared open and u-VATS groups in their analysis and they found results similar to those above mentioned, with significant differences in median blood loss, hospital stay and time to access adjuvant chemotherapy after the operation (29.6 vs. 43.3 days). Gonzalez-Rivas et al. (20) published an analysis on $43 \mathrm{u}$-VATS resections for advanced stage of NSCLC compared to 87 resections for early-stage lung cancer. They found no significant differences between the two groups in terms of in-hospital stay, chest tube removal and rate of complications; overall 30-months survival was $73.7 \%$.

\section{VATS, T4 and (neo)adjuvant therapies}

The overall survival for patients with stage III NSCLC is less than $5 \%$ after 5 years in those undergoing single modality therapy with either radiotherapy or surgery alone (27). Induction therapy is considered the standard of care for patients with operable stage III NSCLC $(28,29)$, with reported 5 -year survival rates between $43 \%$ (30) and $56 \%$ (31) in IIIB stage patients who underwent preoperative chemoradiotherapy. Despite surgeons' concerns about adhesions and the difficult hilar and mediastinal dissection, VATS and u-VATS has proved to be feasible and safe procedures also after neoadjuvant therapies, showing no differences in perioperative outcomes, 30-day mortality and overall survival when compared to open thoracotomy (28,32-34).

Moreover, VATS approach could also promote a faster access to adjuvant therapies and to better tolerate them leading to improved survival rates. This is because VATS is less invasive and painful for patients, allowing a faster recovery. Many studies have highlighted the possible role of VATS in preserving a better functionality of the immune system, because of a less acute inflammatory response after a minimally invasive approach $(21,35)$. Additionally, 


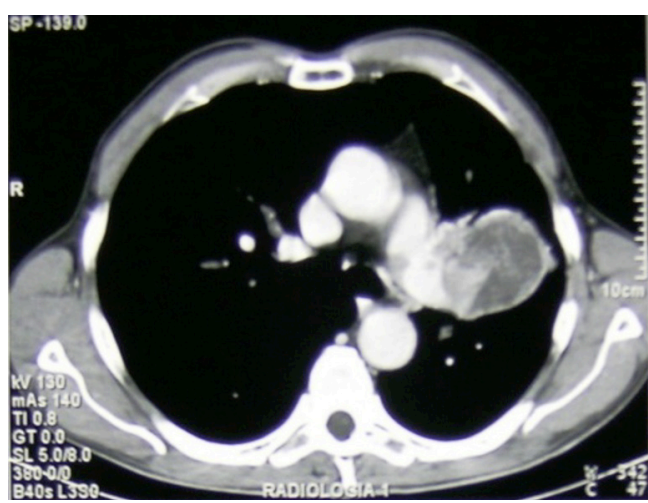

Figure 1 Chest computed tomography scans showing a large central lung cancer.

Peng et al. (36) found that VEGF release from tissues after surgery could have a proangiogenic effect and consequently promote tumor growth and metastasis formation; they also proved that after a VATS resection, levels of VEGF released were lower than after an open thoracotomy. D'Amico (37) published results about the delivery of adjuvant chemotherapy after VATS or open lobectomy for NSCLC; $93.9 \%$ of patients who underwent VATS lobectomy tolerate the complete 3 -cycle adjuvant regimen $v$ s. the $79.1 \%$ of those who underwent open thoracotomy.

\section{Patient selection}

Preoperative staging of T4 lung tumors is of paramount importance to plan the most adequate treatment. Since extended surgical resection could be connected with higher perioperative risks, it has to be indicated on an individual patient basis, excluding those with a marginal cardiopulmonary reserve and low performance status, with age $<70$ years (3). A multidisciplinary board should guide the correct treatment strategy, after nodal and systemic spread had been excluded along with international guidelines. In particular, thoracoscopic procedures should be considered when minimal invasion of adjacent organs occurs and excluded for superior sulcus tumors and bulky, nodal or systemic disease (22).

Along with perioperative assessment of lung function, preoperative TNM staging should include total-body CT scan and positron emission tomography (PET) to better detect unrecognized nodal or metastatic disease. $\mathrm{T}$ status may often result under or overstaged by CT-scan only, since infiltrated structures are not often detectable; in these cases, magnetic resonance (MRI), echocardiography or transesophageal ultrasounds could guide the clinicians' decision. Gdeedo et al. (38) proved that, in their case series, CT staging of T3 and T4 lung cancers was correct in almost 50\% of cases; Cangemi et al. (39) reported similar results; in their series, CT-scan staging for T4 tumors was accurate only in $27 \%$ of cases. Other studies, reported that CT-scan sensitivity for chest wall invasion varies from 38 to $87 \%$ and the specificity varies from $40 \%$ to $90 \%$ (40) vs. MRI sensitivity ranging from 63 to $90 \%$ with a specificity of $84 \%$ to $86 \%$ (41). When used to predict mediastinal invasion, both CT scan and MRI have similar diagnostic accuracy (56-89\% for CT and 50-93\% for MRI), with no modality being considered superior. A recent study by Tang et al. (42) compared T staging accuracy of both MRI and CT-scan; they found that CT was more accurate when studying T1 and T2 NSCLC (100\% vs. $75 \%$, $96.4 \%$ vs. $82.1 \%$ ), while MRI was superior in the identification of T3 and T4 tumors ( $80 \%$ vs. $50 \%, 100 \%$ vs. $33.3 \%$ ).

An interesting suggestion is to use VATS to assess the real extent of the tumor, even if an open thoracotomy is planned, to exclude any contraindication to resection not evident in the preoperative radiological evaluation (43). VATS inspection, in fact, is a non time-consuming and economic procedure which could routinely be performed prior to the open approach. Cetinkaya et al. (44) conducted a study to compare preoperative and postoperative staging in NSCLC; interestingly, in patients with cT4 disease, downstaging occurred in $38.2 \%$ of cases. Mouroux et al. (45) routinely performed VATS inspection in the presence of inconclusive information of imaging techniques about extension and resectability. De Giacomo et al. (46) also performed a study on 64 patients with the clinical suspicion of stage IIIB lung cancer to evaluate the role of VATS in the assessment of the real extent of the tumor. They found that VATS is safe and effective for this purpose and it provided the correct staging for $91 \%$ of patients.

\section{Tumors $>7 \mathrm{~cm}$}

Adhesions, narrow spaces and difficulty to move the lobe, make VATS resection for large lung tumors still poorly practiced and discussed, and it still remains a challenging procedure to perform trough a minimally invasive approach (Figure 1). Hou et al. (47) reported a case report of a VATS left-upper lobectomy, bronchoplasty and angioplasty for a giant central lung cancer, showing how thoracoscopy had been useful firstly for an accurate dissection and then to provide better vision and better chances for recovery along 

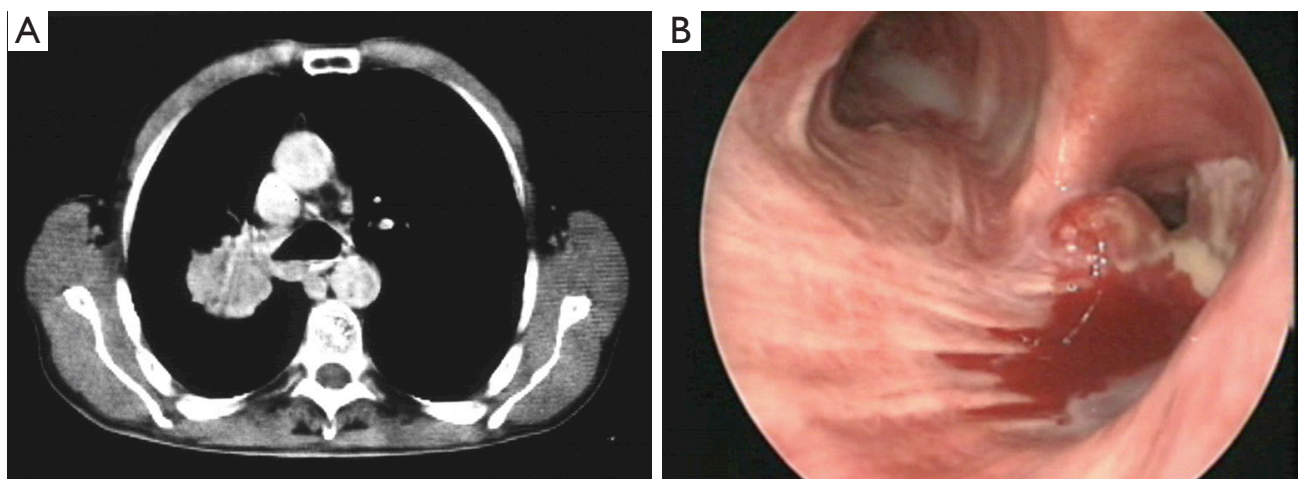

Figure 2 A Chest computed tomography scan showing a tracheal tumor involving the carina and the right main bronchus. B. Bronchoscopic view of the tumor involving the carina and the proximal part of the right main bronchus.

with a complete oncologic resection.

\section{Tumors invading the great vessels, trachea or carina}

In 2002, Santambrogio et al. (48) reported the first videoassisted bronchial sleeve resection and bronchoplasty. Since that, many studies have been published about the role of VATS in bronchoplastic procedures and vascular sleeve resections, sharing the experience and the tips and tricks of skilled surgeons (49-52). Because of its technical difficulty, airway reconstructions are still a challenge even for the most skilled surgeons, and few opportunities are still offered during thoracic training programs to practice endoscopic suturing.

Moreover, central lung cancer involving the carina is still a challenging procedure due to the technical difficulty of carina resection and airway management and reconstruction (Figure 2). Many authors have reported several case reports about thoracoscopic carina resection and reconstruction for central lung cancer, demonstrating the feasibility of this procedure although some issues remain unsolved. Firstly, the correct management of airways during the VATS reconstruction which has to be as much as less interfering with the surgical field while preventing hypercapnia o hypoxemia. Li et al. (53) shared their experience on a series of 12 patients who underwent VATS carinal or tracheal resection and reconstruction for benign or malignant diseases. At the beginning of their experience, after the tracheal resection, they shifted to cross-field ventilation by introducing the endobronchial tube directly through the $4-\mathrm{cm}$ main operative port or an optional $10-\mathrm{mm}$ port. As they became more skilled at the procedure, they also tried to simplify the surgery by using high-frequency jet ventilation (HFJV) or spontaneous breathing anesthesia (SRA). The outcomes of the three procedures have not been compared, but they reported no overall in-hospital mortality or major morbidity.

Cross-field ventilation is a time consuming procedure, since it requires periodical retraction during anastomosis, while it obstructs the view of the surgical field. On the other hand, HFJV may ventilate one lung without causing injury to the tumor, but it can cause moderate lung ventilation and increase the risk for postoperative ARDS $(54,55)$. Three major issues have been described while dealing with SRA: management of airway, hypoxemia and hypercapnia. Jiang et al. (56) compared results on $18 \mathrm{vs.}$ 14 patients who underwent thoracoscopic carina resection both through intubation or spontaneous anesthesia. They proved that SRA could help both the anesthetic and surgical procedure; the lack of an endotracheal tube, in fact, makes the trachea more flexible and allows a wider range of motion for the surgeon, along with a wider field of view; these factors lead to a global reduction of operative time. Ai et al. (57) reported two cases of neoplastic invasion of left main bronchus up to the bifurcation of the upper and lower lobe, the carina and the right main bronchus treated by using a bilateral combined VATS and open approach. Firstly, they performed a right posterolateral thoracotomy to resect and anatomize trachea and the right main bronchus; subsequently, they performed a VATS left sleeve pneumonectomy trough a four-port left thoracoscopy. Although no randomized trials have been performed on this topic and only few case reports have been published, all authors agree that the most important factor influencing the outcomes of such a complex thoracoscopic procedure is the 


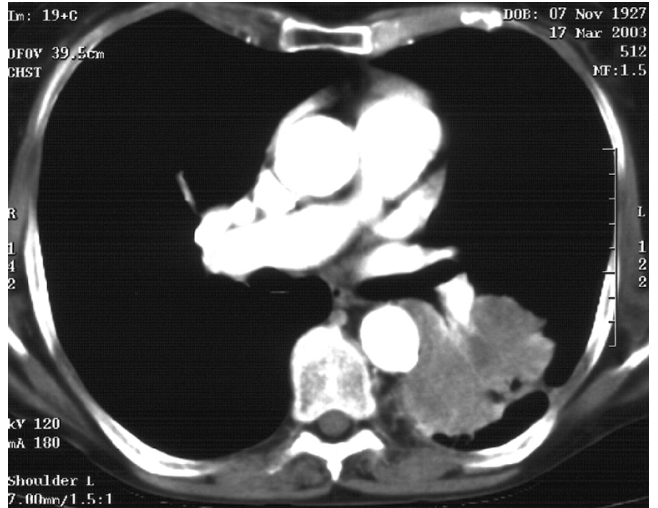

Figure 3 Chest computed tomography scan showing a lung tumor with aortic wall involvement.

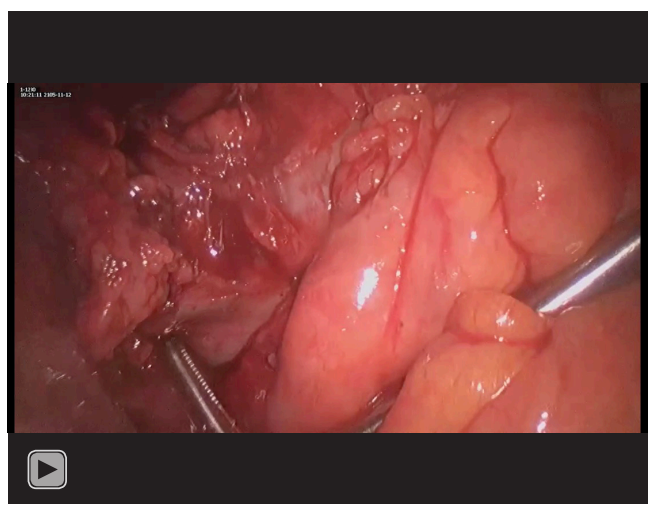

Video 1 Right non-small-cell lung cancer involving the atrium: VATS atriotomy and closure of the atrium using a running suture. VATS, video-assisted thoracic surgery.

careful patient selection (53-57).

Endoscopic bronchial and tracheal anastomosis methods include intermittent, continuous, and continuous mixed with intermittent sutures (58-64). When performing a thoracoscopic procedure, most of authors agree on the usefulness of a complete continuous suture starting from the posterior part of the anastomosis to the anterior one, since it offers a clear operative view (53-57,65-67).

The first case report of a uniportal VATS sleeve resection has been published in 2013 by Gonzalez-Rivas et al. (64) and new attempts have been reported $(68,69)$ confirming the possible advantages in terms of minimal invasiveness, lower postoperative pain and good postoperative outcomes. In a review published in 2015, Gonzalez-Rivas et al. (49) described their anastomotic technique for uniportal-VATS carina resection, using both a cross-field tube and HFJV.

To date, few cases have been reported about the possible role of VATS when managing tumors infiltrating the great vessels (70-75) (Figure 3). Surgery in these cases is still challenging both because of technical problems and difficulty in accomplishing a radical resection. VATS approach is unusual and complex in these cases, because of the limited working space and surgical field. In fact, different techniques have been described to perform safe vascular resections, including cardiopulmonary bypass (CBP), aorto-aortic passive shunt, direct clamping or thoracic aortic endograft (Video 1). Each technique should be chosen based on length, depth and site of aortic involvement and on the type of resection to be performed; if more than one fourth of the wall has to be resected a patching or a complete resection followed by an end-to-end anastomosis should be performed (76). Nakanishi et al. (71) reported their experience on a case series of 5 patients who underwent a VATS lobectomy with pulmonary artery (PA) angioplasty. They used a four-port approach, using a $7-\mathrm{cm}$ utility thoracotomy incision in the $3 \mathrm{rd}$ or 4 th intercostal space to insert the Satinsky clamps on the proximal and distal part of PA; after that, the infiltrated wall of the artery was resected by using scissors and reconstructed with a running Prolene suture. Xu et al. (72), instead, described their VATS technique when the side-wall of the pulmonary trunk is infiltrated, by performing an arterioplasty using a mechanical suturing technique. Gonzalez-Rivas et al. (49) suggested some tricks to perform uniportal-VATS angioplasty for advanced lung cancer: the use of bulldog clamps on the pulmonary vessels as they do not interfere with other instruments; the use of a double-vessel loop to clamp the distal artery for partial resections; to perform vascular reconstruction during the last step of the lobectomy in order to have a larger surgical field.

CBP should be used in case of aortic arch/supraortic vessel involvement, when the media is invaded and resection requires cross-clamping of the aorta to resect the infiltrated wall (77) and obviously it cannot be used in VATS. Marulli et al. (78) in 2008 firstly described a two-step use of a thoracic endovascular graft followed by delayed en bloc surgical resection of the tumor to avoid CBP, aortic clamping, resection and vascular graft anastomoses, lowering the peri- and postoperative complication rates (77). Since in the majority of cases aortic infiltration is confined to the adventitia, the preoperative thoracic endograft positioning could be used to perform a VATS en bloc resection of the tumor since no need for clamping or 
CBP should be required. Unfortunately, no attempts have been performed in this field, yet. Additionally, since the techniques to perform safe and radical vessel resections are different and have to be chosen based on the entity of the infiltration, inspective VATS could be a helpful means to complete preoperative staging to decide what kind of procedure is the best to be planned.

\section{Pancoast's and tumors invading the spine, chest wall or diaphragm}

Many hybrid approaches have been proposed in Literature to obtain both an oncological and a minimally invasive resection for tumors involving the chest wall and Pancoast tumors (Figures 4,5). All these approaches agree on the first, important role of VATS: an initial thoracoscopy to evaluate the resectability and the real extent of the tumor. Additionally, the minimally invasive approach may be used to perform lobectomy and to better define the extent of chest wall resection.

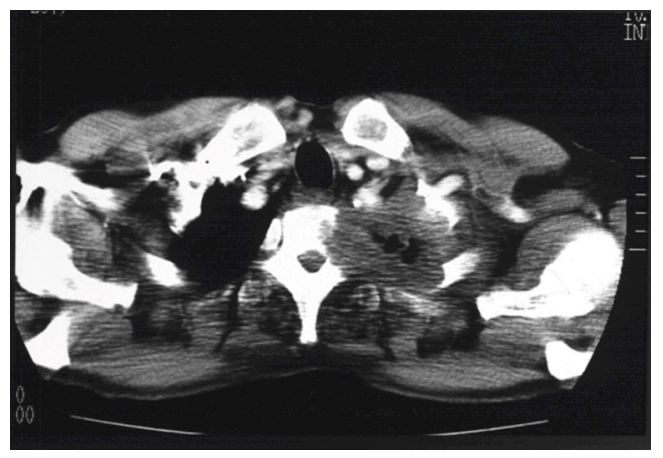

Figure 4 Chest computed tomography scan showing an apical chest wall tumor with spinal involvement.
Truin et al. (79) reported for the first time a hybrid VATS approach for superior sulcus tumors, combining VATS with a L-shaped transmanubrial incision according to Grunenwald to perform an anterior radical dissection. Rosso et al. $(80,81)$ also proposed two hybrid combined approaches with both a limited Shaw-Paulson thoracotomy and a modified Grunenwald incision, paving the way to new creative minimally invasive approaches. Moreover, Caronia et al. (82) performed a comparative analysis of Pancoast tumor resection performed via VATS or open approaches. They used VATS to firstly observe the extent of the tumor, then they performed an anterior or posterior thoracotomy with video-assistance support or a VATS lobectomy followed by chest-wall resection. The two groups were equivalent regarding blood transfusion, chest drain duration and length of hospital stay, but there was a significant difference in intraoperative blood loss and in morphine requirement in favor of the VATS group.

Stoker et al. (83) reported their results on eight consecutive patients who underwent VATS or open thoracotomy with simultaneous posterior spine reconstruction (PSR) for invasive upper lobe lung cancer. Even if preliminary, they described encouraging results for this innovative technique, with lower perioperative complications and shorter in-hospital stay when comparing the VATS with the open approach.

Although many studies have proved the feasibility of a VATS approach for plication of the diaphragm after repair or eventration, (84-91) the first experience of a uniportalVATS resection of NSCLC invading the diaphragm has been firstly described by Gonzalez-Rivas et al. (92) in 2019.

Through a single five-centimeter anterior incision at the fifth intercostal space, in 8 cases they resected the involved part of the diaphragm at the beginning or at the end of the surgery, closing the remaining defect with continuous non-
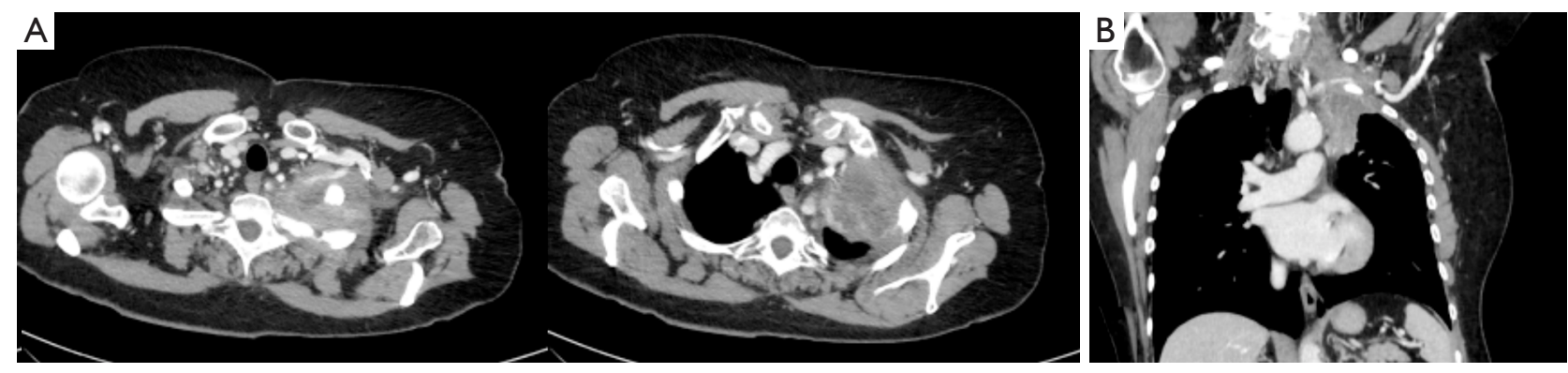

Figure 5 Pancoast tumor. Axial (A) and coronal (B) computed tomography scans reveal a superior sulcus tumor invading the ipsilateral subclavian artery. 


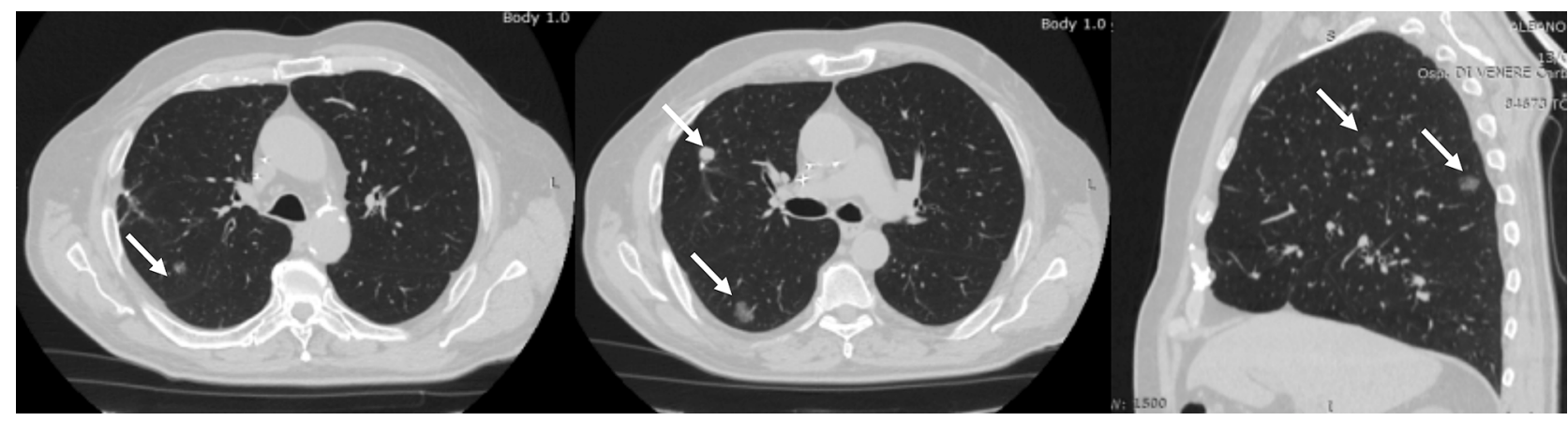

Figure 6 Chest computed tomographic images revealing simultaneous lung nodules and ground-glass opacities (white arrows) in the right upper and lower lobes.

absorbable sutures or synthetic patches on the basis of the entity of the defect itself.

\section{Tumors with separate tumor nodule(s) in a different ipsilateral lobe}

Surgical resection of multifocal NSCLC has been widely discussed and approved by several previous studies $(93,94)$. Because of the type of surgery required (including lobectomy, sublobectomy, bilobectomy or pneumonectomy), this indication seems to be the most appropriate for a VATS approach. The extension of the resections has to be accurately evaluated for each patient, on both the basis of number, size and location of the lesions and of patients' adequate cardiopulmonary reserve and performance status (Figure 6). Many studies had also proved the feasibility of thoracoscopic pneumonectomy (95-99) as a safe procedure with equivalent results when compared to the open approach, but able to lower pain score since no chest retractor is used. Also, an animal study by Liu et al. (100) confirmed that postoperative stress was lower in pigs that underwent VATS pneumonectomy when compared with thoracotomy.

\section{Conclusions}

The role of VATS in T4 NSCLC is both for diagnostic and therapeutic purposes. In the hands of skillful surgeons, VATS resections for T4 tumors could be a promising instrument to perform complete resections, allowing lower postoperative pain, shorter hospitalization and faster recovery. Most of published studies have proved no statistical differences in median blood loss, operative time, frequency of major complications, in-hospital stay when comparing VATS and open approach for T4 tumors.
Likely, VATS resections could increase the overall survival in advanced lung cancer allowing patients to better tolerate adjuvant treatments at the fully planned dose. Many attempts have been done during the last years to approach $\mathrm{T} 4$ tumors in a minimally invasive way and first results are promising, even if it is evident that these procedures have to be performed by skilled surgeons in specialized centers. Because of the exiguity of available cases, these evidences largely originate from cases reports or retrospective studies and more randomized clinical trials and comparative studies are needed to confirm these preliminary results.

\section{Acknowledgments}

Funding: None.

\section{Footnote}

Provenance and Peer Review: This article was commissioned by the Guest Editor (Federico Rea) for the series "Alternative Surgical Approaches for Challenging Cases in Thoracic Surgery" published in Fournal of Visualized Surgery. The article has undergone external peer review.

Conflicts of Interest: All authors have completed the ICMJE uniform disclosure form (available at https:// jovs.amegroups.com/article/view/10.21037/jovs-20-93/ coif). The series "Alternative Surgical Approaches for Challenging Cases in Thoracic Surgery" was commissioned by the editorial office without any funding or sponsorship. The authors have no other conflicts of interest to declare.

Ethical statement: The authors are accountable for all aspects of the work in ensuring that questions related 
to the accuracy or integrity of any part of the work are appropriately investigated and resolved. All procedures performed in this study were in accordance with the Helsinki Declaration (as revised in 2013). The manuscript is waived from patient informed consent according to the ethics committee or institutional review board.

Open Access Statement: This is an Open Access article distributed in accordance with the Creative Commons Attribution-NonCommercial-NoDerivs 4.0 International License (CC BY-NC-ND 4.0), which permits the noncommercial replication and distribution of the article with the strict proviso that no changes or edits are made and the original work is properly cited (including links to both the formal publication through the relevant DOI and the license). See: https://creativecommons.org/licenses/by-nc-nd/4.0/.

\section{References}

1. Rami-Porta R, Bolejack V, Crowley J, et al. The IASLC Lung Cancer Staging Project: Proposals for the Revisions of the T Descriptors in the Forthcoming Eighth Edition of the TNM Classification for Lung Cancer. J Thorac Oncol 2015;10:990-1003.

2. Ilonen I, Jones DR. Initial extended resection or neoadjuvant therapy for T4 non-small cell lung cancerWhat is the evidence? Shanghai Chest 2018;2:76.

3. DiPerna CA, Wood DE. Surgical management of T3 and T4 lung cancer. Clin Cancer Res 2005;11:5038s-44s.

4. De Ruysscher D, Faivre-Finn C, Nestle U, et al. European Organisation for Research and Treatment of Cancer recommendations for planning and delivery of high-dose, high-precision radiotherapy for lung cancer. J Clin Oncol 2010;28:5301-10.

5. Mo Y, Peng J, Su W, et al. Controversies regarding T status and $\mathrm{N}$ status for non-small cell lung cancer. Int J Clin Exp Med 2015;8:11675-82.

6. Dartevelle PG. Herbert Sloan Lecture. Extended operations for the treatment of lung cancer. Ann Thorac Surg 1997;63:12-9.

7. Rice TW, Blackstone EH. Radical resections for T4 lung cancer. Surg Clin North Am 2002;82:573-87.

8. Goldstraw P, Chansky K, Crowley J, et al. The IASLC Lung Cancer Staging Project: Proposals for Revision of the TNM Stage Groupings in the Forthcoming (Eighth) Edition of the TNM Classification for Lung Cancer. J Thorac Oncol 2016;11:39-51.

9. Wu L, Zhifei X, Zhao X, et al. Surgical treatment of lung cancer invading the left atrium or base of the pulmonary vein. World J Surg 2009;33:492-6.

10. Yang HX, Hou X, Lin P, et al. Survival and risk factors of surgically treated mediastinal invasion T4 non-small cell lung cancer. Ann Thorac Surg 2009;88:372.

11. Pitz CC, Brutel de la Rivière A, van Swieten HA, et al. Results of surgical treatment of T4 non-small cell lung cancer. Eur J Cardiothorac Surg 2003;24:1013-8.

12. Mu JW, Wang YG, Li J, et al. Surgical results of T4 lung cancer invading left atrium and great vessels. Zhonghua Yi Xue Za Zhi 2008;88:383-6.

13. Wang XX, Liu TL, Yin XR. Surgical treatment of IIIb-T4 lung cancer invading left atrium and great vessels. Chin Med J (Engl) 2010;123:265-8.

14. Demmy TL, Curtis JJ. Minimally invasive lobectomy is a safe and versatile procedure: experience with 500 consecutive patients. Ann Thorac Surg 1999;68:194-200.

15. McKenna RJ, Houck W, Fuller CB. Video-assisted thoracic surgery lobectomy: experience with 1,100 cases. Ann Thorac Surg 2006;81:421-5.

16. Onaitis MW, Petersen PR, Balderson SS, et al. Thoracoscopic lobectomy is a safe and versatile procedure: experience with 500 consecutive patients. Ann Surg 2006;244:420-5.

17. Nicastri DG, Wisnivesky JP, Litle VR, et al. Thoracoscopic lobectomy: report on safety, discharge independence, pain and chemotherapy tolerance. J Thorac Cardiovasc Surg 2008;135:642-7.

18. Nagahiro I, Andou A, Aoe M, et al. Pulmonary function, postoperative pain, and serum cytokine level after lobectomy: a comparison of VATS and conventional procedure. Ann Thorac Surg 2001;72:362-5.

19. Swanson SJ, Herndon JE 2nd, D'Amico TA, et al. Videoassisted thoracic surgery lobectomy: report of CALGB 39802: a prospective, multi-institution feasibility study. J Clin Oncol 2007;25:4993-7.

20. Gonzalez-Rivas D, Fieira E, Delgado M, et al. Is uniportal thoracoscopic surgery a feasible approach for advanced stages of non-small cell lung cancer? J Thorac Dis 2014;6:641-8.

21. Hennon MW, Demmy TL. Video-assisted thoracoscopic surgery (VATS) for locally advanced lung cancer. Ann Cardiothorac Surg 2012;1:37-42.

22. Nakanishi R, Fujino Y, Yamashita T, et al. Thoracoscopic anatomic pulmonary resection for locally advanced nonsmall cell lung cancer. Ann Thorac Surg 2014;97:980-5.

23. Chen K, Wang X, Yang F, et al. Propensity-matched comparison of video-assisted thoracoscopic with 
thoracotomy lobectomy for locally advanced non-small cell lung cancer. J Thorac Cardiovasc Surg 2017;153:96776.e2.

24. Gonfiotti A, Bongiolatti S, Bertolaccini L, et al. Thoracoscopic lobectomy for locally advanced-stage nonsmall cell lung cancer is a feasible and safe approach: analysis from multi-institutional national database. J Vis Surg 2017;3:160.

25. Zhang L. Short- and long-term outcomes in elderly patients with locally advanced non-small-cell lung cancer treated using video-assisted thoracic surgery lobectomy. Ther Clin Risk Manag 2018;14:2213-20.

26. Fan J, Yao J, Wang Q, et al. Safety and feasibility of uniportal video-assisted thoracoscopic surgery for locally advanced non-small cell lung cancer. J Thorac Dis 2016;8:3543-50.

27. Martini N, Kris MG, Flehinger BJ, et al. Preoperative chemotherapy for stage IIIa (N2) lung cancer: the SloanKettering experience with 136 patients. Ann Thorac Surg 1993;55:1365-73.

28. Petersen RP, Pham D, Toloza EM, et al. Thoracoscopic lobectomy: a safe and effective strategy for patients receiving induction therapy for non-small cell lung cancer. Ann Thorac Surg 2006;82:214-8.

29. Garrido P, González-Larriba JL, Insa A, et al. Long-term survival associated with complete resection after induction chemotherapy in stage IIIA (N2) and IIIB (T4N0-1) non small-cell lung cancer patients: the Spanish Lung Cancer Group Trial 9901. J Clin Oncol 2007;25:4736-42.

30. Stamatis G, Eberhardt W, Stuben G, et al. Preoperative chemoradiotherapy and surgery for selected non-small cell lung cancer IIIB subgroups: Long-term results. Ann Thorac Surg 1999;68:1144-9.

31. Ichinose $Y$, Fukuyama $Y$, Asoh H, et al. Induction chemoradiotherapy and surgical resection for selected stage IIIB non-small-cell lung cancer. Ann Thorac Surg 2003;76:1810-4.

32. Yang C-FJ, Meyerhoff RR, Mayne NR, et al. Long-term survival following open versus thoracoscopic lobectomy after preoperative chemotherapy for non-small cell lung cancer. Eur J Cardiothorac Surg 2016;49:1615-23.

33. Huang J, Xu X, Chen H, et al. Feasibility of complete video-assisted thoracoscopic surgery following neoadjuvant therapy for locally advanced non-small cell lung cancer. J Thorac Dis 2013;5:S267-73.

34. Yang Z, Zhai C. Uniportal video-assisted thoracoscopic surgery following neoadjuvant chemotherapy for locallyadvanced lung cancer. J Cardiothorac Surg 2018;13:33.
35. Ng CS, Lau KK. Surgical trauma and immune functional changes following major lung resection. Indian J Surg 2015;77:49-54.

36. Peng J, An S, Wang HP, et al. Video-assisted thoracoscopic surgery lobectomy for lung cancer versus thoracotomy: a less decrease in sVEGFR2 level after surgery. J Thorac Dis 2016;8:323-8.

37. D'Amico TA. VATS lobectomy facilitates the delivery of adjuvant docetaxel-carboplatin chemotherapy in patients with non-small cell lung cancer. J Thorac Dis 2016;8:296-7.

38. Gdeedo A, Van Schil P, Corthouts B, et al. Prospective evaluation of computed tomography and mediastinoscopy in mediastinal lymph node staging. Eur Respir J 1997;10:1547-51.

39. Cangemi V, Volpino P, Drudi FM, et al. Assessment of the accuracy of diagnostic chest CT scanning. Impact on lung cancer management. Int Surg 1996;81:77-82.

40. Quint LE, Francis IR. Radiologic staging of lung cancer. J Thorac Imaging 1999;14:235-46.

41. Padovani B, Mouroux J, Seksik L, et al. Chest wall invasion by bronchogenic carcinoma: evaluation with MR imaging. Radiology 1993;187:33-8.

42. Tang $W, W u ~ N$, OuYang $H$, et al. The presurgical T staging of non-small cell lung cancer: efficacy comparison of 64-MDCT and 3.0 T MRI. Cancer Imaging 2015;15:14.

43. Hennon M, Sahai RK, Yendamuri S, et al. Safety of thoracoscopic lobectomy in locally advanced lung cancer. Ann Surg Oncol 2011;18:3732-6.

44. Cetinkaya E, Turna A, Yildiz P, et al. Comparison of clinical and surgical-pathologic staging of the patients with non-small cell lung carcinoma. Eur J Cardiothorac Surg 2002;22:1000-5.

45. Mouroux J, Venissac N, Alifano M. Combined videoassisted mediastinoscopy and video-assisted thoracoscopy in the management of lung cancer. Ann Thorac Surg 2001;72:1698-704.

46. De Giacomo T, Rendina EA, Venuta F, et al. Thoracoscopic staging of IIIB non-small cell lung cancer before neoadjuvant therapy. Ann Thorac Surg 1997;64:1409-11.

47. Hou GJ, He Y, Zhao P. Video-assisted thoracoscopic left upper lobectomy and broncho-and-angioplasty for a giant central lung cancer complicated with intratumoral abscess: one case report. J Thorac Dis 2018;10:4484-6.

48. Santambrogio L, Cioffi U, De Simone M, et al. Videoassisted sleeve lobectomy for mucoepidermoid carcinoma of the left lower lobar bronchus: a case report. Chest 2002;121:635-6. 
49. Gonzalez-Rivas D, Yang Y, Stupnik T, et al. Uniportal video-assisted thoracoscopic bronchovascular, tracheal and carinal sleeve resections. Eur J Cardiothorac Surg 2016;49:6-16.

50. Gonzalez-Rivas D, Yang Y, Sekhniaidze D, et al. Uniportal video-assisted thoracoscopic bronchoplastic and carinal sleeve procedures. J Thorac Dis 2016;8:S210-22.

51. Xu X, Chen H, Yin W, et al. Thoracoscopic half carina resection and bronchial sleeve resection for central lung cancer. Surg Innov 2014;21:481-6.

52. Abu Akar F, Yang C, Lin L, et al. Intra-pericardial double sleeve uniportal video-assisted thoracoscopic surgery left upper lobectomy. J Vis Surg 2017;3:51.

53. Li J, Wang W, Jiang L, et al. Video-Assisted Thoracic Surgery Resection and Reconstruction of Carina and Trachea for Malignant or Benign Disease in 12 Patients: Three Centers' Experience in China. Ann Thorac Surg 2016;102:295-303.

54. He J, Wang W, Li J, et al. Video-assisted thoracoscopic surgery tracheal resection and carinal reconstruction for tracheal adenoid cystic carcinoma. J Thorac Dis 2016;8:198-203.

55. Porhanov VA, Poliakov IS, Selvaschuk AP, et al. Indications and results of sleeve carinal resection. Eur J Cardiothorac Surg 2002;22:685-94.

56. Jiang L, Liu J, Gonzalez-Rivas D, et al. Thoracoscopic surgery for tracheal and carinal resection and reconstruction under spontaneous ventilation. J Thorac Cardiovasc Surg 2018;155:2746-54.

57. Ai B, Liao Y, Zhang Z, et al. Single-stage bilateral thoracic surgery via a combined VATS and open approach for left central bronchogenic carcinoma with carinal invasion: report of two cases. J Cardiothorac Surg 2015;10:76.

58. Mahtabifard A, Fuller CB, McKenna RJ Jr. Video-assisted thoracic surgery sleeve lobectomy: a case series. Ann Thorac Surg 2008;85:S729-32.

59. Agasthian T. Initial experience with video-assisted thoracoscopic bronchoplasty. Eur J Cardiothorac Surg 2013;44:616-23.

60. Huang J, Li S, Hao Z, et al. Complete video-assisted thoracoscopic surgery (VATS) bronchial sleeve lobectomy. J Thorac Dis 2016;8:553-74.

61. Han Y, Zhou S, Yu D, et al. Video-assisted thoracic surgery (VATS) left upper sleeve lobectomy with partial pulmonary artery resection. J Thorac Dis 2013;5:S301-3.

62. Liu K, Jin C, Tian H, et al. Total video-assisted thoracic surgery sleeve lobectomy: suture by both hands. Thorac Cardiovasc Surg Rep 2013;2:43-5.
63. Li Y, Wang J. Video-assisted thoracoscopic surgery sleeve lobectomy with bronchoplasty: an improved operative technique. Eur J Cardiothorac Surg 2013;44:1108-12.

64. Gonzalez-Rivas D, Fernandez R, Fieira E, et al. Uniportal video-assisted thoracoscopic bronchial sleeve lobectomy: first report. J Thorac Cardiovasc Surg 2013;145:1676-7.

65. Ohata K, Zhang J, Ito S, Yoshimura T, et al. Thoracoscopic bronchoplasty using continuous sutures in complete monitor view. Ann Thorac Surg 2014;98:1132-3.

66. Shao F, Liu Z, Pan Y, et al. Bronchoplasty using continuous suture in complete monitor view: a suitable method of thoracoscopic sleeve lobectomy for non-small cell lung cancer. World J Surg Oncol 2016;14:134.

67. Davoli F, Bertolaccini L, Pardolesi A, et al. Video-assisted thoracoscopic surgery bronchial sleeve lobectomy. J Vis Surg 2017;3:41.

68. Koryllos A, Stoelben E. Uniportal video-assisted thoracoscopic surgery (VATS) sleeve resections for nonsmall cell lung cancer patients: an observational prospective study and technique analysis. J Vis Surg 2018;4:16.

69. Aim A, Almre I, Vanakesa T. Combined approach using uniportal video-assisted thoracoscopic surgery in left tracheal sleeve pneumonectomy. J Thorac Dis 2018;10:E584-6.

70. Jiao W, Zhao Y, Wang X, et al. Video-assisted thoracoscopic left upper lobe sleeve lobectomy combined with pulmonary arterioplasty via two-port approach. J Thorac Dis 2014;6:1813-5.

71. Nakanishi R, Yamashita T, Oka S. Initial experience of video-assisted thoracic surgery lobectomy with partial removal of the pulmonary artery. Interact CardioVasc Thorac Surg 2008;7:996-1000.

72. Xu X, Huang J, Yin W, et al. He J. Pulmonary arterioplasty using video-assisted thoracic surgery mechanical suture technique. J Thorac Dis 2016;8:617-27.

73. Shao W, Yin W, Wang W, et al. Glasses-free threedimensional endoscopic bronchoplasty, arterioplasty, and angioplasty of the superior vena cava for the radical treatment of right middle upper lung cancer. J Thorac Dis 2016;8:608-11.

74. Xu K, Zhang Z, Zhao J, et al. Partial removal of the pulmonary artery in video-assisted thoracic surgery for non-small cell lung cancer. J Biomed Res 2013;27:310-7.

75. Yu DP, Han Y, Zhao QY, et al. Pulmonary lobectomy combined with pulmonary arterioplasty by complete videoassisted thoracic surgery in patients with lung cancer. Asian Pac J Cancer Prev 2013;14:6061-4.

76. Cerfolio RJ, Bryant AS. Surgical techniques and results for 
partial or circumferential sleeve resection of the pulmonary artery for patients with non-small cell lung cancer. Ann Thorac Surg 2007;83:1971-6.

77. Marulli G, Rendina EA, Klepetko W, et al. Surgery for T4 lung cancer invading the thoracic aorta: Do we push the limits? J Surg Oncol 2017;116:1141-9.

78. Marulli G, Lepidi S, Frigatti P, et al. Thoracic aorta endograft as an adjunct to resection of a locally invasive tumor: a new indication to endograft. J Vasc Surg 2008;47:868-70.

79. Truin W, Siebenga J, Belgers E, et al. The role of videoassisted thoracic surgery in the surgical treatment of superior sulcus tumors. Interact Cardiovasc Thorac Surg 2010;11:512-4.

80. Rosso L, Nosotti M, Palleschi A, et al. VATS lobectomy combined with limited Shaw-Paulson thoracotomy for posterolateral Pancoast tumor. Tumori 2016;102. doi:10.5301/tj.5000430.

81. Rosso L, Palleschi A, Mendogni P, et al. Video-assisted pulmonary lobectomy combined with transmanubrial approach for anterior Pancoast tumor resection: case report. J Cardiothorac Surg 2016;11:65.

82. Caronia FP, Fiorelli A, Ruffini E, et al. A comparative analysis of Pancoast tumour resection performed via videoassisted thoracic surgery versus standard open approaches. Interact Cardiovasc Thorac Surg 2014;19:426-35.

83. Stoker GE, Buchowski JM, Kelly MP, et al. Video-assisted thoracoscopic surgery with posterior spinal reconstruction for the resection of upper lobe lung tumors involving the spine. Spine J 2013;13:68-76.

84. Moon SW, Wang YP, Kim YW, et al. Thoracoscopic plication of diaphragmatic eventration using endostaplers. Ann Thorac Surg 2000;70:299-300.

85. Shary TM, Hebra A. A simple technique for thoracoscopic treatment of diaphragmatic eventration. Am Surg 2013;79:893-5.

86. Ikeda M, Sonobe M, Bando T, et al. Reconstruction of recurrent diaphragmatic eventration with an elongated polytetrafluoroethylene sheet. Interact Cardiovasc Thorac Surg 2013;17:433-5.

87. Kara HV, Roach MJ, Balderson SS, et al. Thoracoscopic diaphragm plication. Ann Cardiothorac Surg 2015;4:573-5.

88. Dunning J. Thoracoscopic diaphragm plication. Interact Cardiovasc Thorac Surg 2015;20:689-90.

89. Wu HH, Chen $\mathrm{CH}$, Chang $\mathrm{H}$, et al. A preliminary report on the feasibility of single-port thoracoscopic surgery for diaphragm plication in the treatment of diaphragm eventration. J Cardiothorac Surg 2013;8:224.

90. Ahn JH, Suh JH, Jeong JY. Robot-assisted thoracoscopic surgery with simple laparoscopy for diaphragm eventration. Thorac Cardiovasc Surg 2013;61:499-501.

91. Peng Y, Ren W, Wang H, et al. Surgical treatment is an effective approach for patients with synchronous multiple primary lung cancers. J Cancer Res Ther 2017;13:702-6.

92. Gonzalez-Rivas D, Ng CSH, Rocco G, et al. editors. Atlas of Uniportal Video Assisted Thoracic Surgery. Springer, 2019:213-22.

93. Okada M, Tsubota N, Yoshimura M, et al. Operative approach for multiple primary lung carcinomas. J Thorac Cardiovasc Surg 1998;115:836-40.

94. Battafarano RJ, Meyers BF, Guthrie TJ, et al. Surgical resection of multifocal non-small cell lung cancer is associated with prolonged survival. Ann Thorac Surg 2002;74:988-93; discussion 993-4.

95. Sahai RK, Nwogu CE, Yendamuri S, et al. Is thoracoscopic pneumonectomy safe? Ann Thorac Surg 2009;88:1086-92.

96. Halezeroğlu S. Single incision video-assisted thoracic surgery pneumonectomy for centrally located lung cancer. Future Oncol 2018;14:41-5.

97. Hennon MW, Demmy TL. Technique of video-assisted thoracoscopic surgery (VATS) left pneumonectomy. Asvide 2017. doi: 10.21037/asvide.2017.105. Available online: http://www.asvide.com/articles/1413

98. Nwogu CE, Yendamuri S, Demmy TL. Does thoracoscopic pneumonectomy for lung cancer affect survival? Ann Thorac Surg 2010;89:S2102-6.

99. Battoo A, Jahan A, Yang Z, et al. Thoracoscopic pneumonectomy: an 11-year experience. Chest 2014;146:1300-1309.

100.Liu HF, Gao L, Liu T, Yan-Jiang, Wang HB. Comparison of acute phase reaction and postoperative stress in pigs undergoing video-assisted thoracoscopic versus thoracotomy pneumonectomy. Acta Vet Scand 2016;58:75.

doi: 10.21037 /jovs-20-93

Cite this article as: Brascia D, De Iaco G, Schiavone M, Nicotra S, Signore F, Panza T, Geronimo A, Sampietro D, Marulli G. Role of video-assisted thoracic surgery in T4 NSCLC. J Vis Surg 2021;7:27. 